\title{
Encontro da multiplicidade na sobremodernidade nas geofotografias do ser-mangue na ZEIS - Ilha de Deus, Recife-PE
}

\section{Meeting of the multiplicity in supermodernity in the geo-photographies of the being- mangrove in the ZEIS - Ilha de Deus, Recife-PE}

\section{Encuentro del multiplicidad en la supermodernidad en las geofotografías del ser- mangle en la ZEIS - Ilha de Deus, Recife-PE}

Luiz Carlos da Silva Filho https://orcid.org/0000-0002-3621-3740 ${ }^{1}$

\footnotetext{
${ }^{1}$ Programa de Pós-graduação em Geografia — PPGE/UFRN, Natal, Rio Grande do Norte, Brasil, luizcarloss246@ gmail.com
}

\section{Resumo}

Percorre por cidades existentes, a partir de uma visão sobremoderna, podemos encontrar vestígios de espaços colocados em uma solidão gerida pelo coletivo hegemônico. Produzindo não-lugares, espaços vazios e - como identificamos - espaços esvaziados ou lugares-assignificativos. Sob esse ponto de vista, o presente trabalho visa encontrar pela razão esquizoanalítica $n-1$ as multiplicidades de vínculos existentes na captura da paisagem cristalizada e materializada na representação visual-documental dos espaços esvaziados promovidos pela sobremodernidade na ZEIS - Ilha de Deus. Utilizamos a etnocartografia e a geofotografia como possibilidade metodológica para compreender e dar visibilidade às multiplicidades existentes. Encontramos a existência transitória de corpora em multiplicidade na Ilha de Deus. O uno torn-se múltiplo em um lugar ressignificado, passando de lugares assignificativos à um lugar significativo.

Palavras-chave: Multiplicidade. Sobremodernidade. Geofotografia. Ser-mangue. Ilha de Deus.

\begin{abstract}
It travels through existing cities, from a supermodern view; we can find traces of spaces placed in a solitude managed by the hegemonic collective. Producing non-places, empty spaces and - as we identify - empty spaces or meaningless-places. From this point of view, the present work aims to find, through schizoanalytic reason $n-1$, the multiplicities of links existing in the capture of the crystallized landscape and materialized in the visual-documental representation of the emptied spaces promoted by supermodernity in ZEIS - Ilha de Deus. We use ethnocartography and geophotography as a methodological possibility to understand and give visibility to the existing multiplicities. We find the transitory existence of corpora in multiplicity in Ilha de Deus. The one becomes multiple in a re-signified place, going from signifying places to a significant place.
\end{abstract}


Keywords: Multiplicity. Supermodernity. Geophotografies. Being-mangrove. Ilha de Deus.

\section{Resumen}

Percorre por cidades existentes, a partir de uma visão sobremoderna, podemos encontrar vestígios de espaços colocados em uma solidão gerida pelo coletivo hegemônico. Produzindo não-lugares, espaços vazios e - como identificamos - espaços esvaziados ou lugares-assignificativos. Sob esse ponto de vista, o presente trabalho visa encontrar pela razão esquizoanalítica $n-1$ as multiplicidades de vínculos existentes na captura da paisagem cristalizada e materializada na representação visual-documental dos espaços esvaziados promovidos pela sobremodernidade na ZEIS - Ilha de Deus. Utilizamos a etnocartografia e a geofotografia como possibilidade metodológica para compreender e dar visibilidade às multiplicidades existentes. Encontramos a existência transitória de corpora em multiplicidade na Ilha de Deus. O uno torn-se múltiplo em um lugar ressignificado, passando de lugares assignificativos à um lugar significativo.

Palabras clave: Multiplicidad. Supermodernidad. Geofotografías. Ser-mangle. Ilha de Deus.

\section{Introdução}

Pensando em sobremodernidade a partir de Augé (1994, 2006) encontramos vestígios de espaços que são reconfigurados para uma solidão agenciada pelo coletivo hegemônico ao transitar pela cidade. Os corpora que permanecem em determinados espaços da cidade são esquecidos pelos valores atribuídos a eles, são forçados a viver em um pseudo-isolamento-de-contatos das relações com o externo - o contato como processo de comunicação e construção de afetividade.

Marandola Jr (2014, p.XVII) no diz que o "lugar, em seus vários espaços e sentidos, é uma ideia-chave para enfrentar os desafios cotidianos. É no lugar que os problemas nos atingem de forma mais dolorida e é também nele que podemos melhor nos fortalecer". Lívia de Oliveira (2014, p. 5) nos diz que a "concepção atual de lugar é de tempo em espaço; ou seja, lugar é tempo lugarizado, pois entre espaço e tempo se dá o lugar, o movimento, a matéria". Portanto, “uma vez que esse espaço em que nos movemos e nos locomovemos, integrante de nossa vida diária, é de fato o nosso lugar" onde desenvolveremos um sentimento topofílico ou topofóbico ao conhecer e fazer parte dele, ou seja, quando cria-se um significado íntimo e 
SILVA FILHO, L.C. da

profundo. É o lugar na geografia humana onde se vivencia e se relaciona com os outros que os cercam.

Em alguns espaços por mais que sejam encontradas relações não-solitária, afetivas e conectivas, são interpeladas por outros como apenas local de passagem e de estranhamento, lugares de esvaziamento de existências. Um não-lugar imaginado pela premissa de não conhecer, já que o uso que fará o lugar ou o não-lugar (AUGÉ, 2006).

O conceito de não-lugar é explorado por Baumman em Modernidade Liquida, onde diz que "os não-lugares aceitam a inevitabilidade de uma adiada passagem, às vezes muito longa, de estranhos, e fazem o que podem para que sua presença seja 'meramente física'" sem relações afetivas ocupam tantos espaços na cidade (BAUMAN, 2001, p. 99).

Embora esses não-lugares sejam espaços de inexistência - para uns- de afetividade e relações, surge também a possibilidade de pensarmos em espaços vazios. Esvaziados por uma outra lógica apresentada na compreensão dos nãolugares. Os não-lugares mesmo que na inexistência de produções afetivas e de comunicação interpessoal, existe um significado e atribuições lógicas na funcionalidade da cidade - servem de passagem mesmo que assignificativas.

Ao falarmos de espaços vazios vamos de encontro a produção assignificante higienizante dos espaços que compõe a cidade. Na visão de Bauman (2001):

Os espaços vazios são antes de mais nada vazios de significado. Não que sejam sem significado porque são vazios: é porque não têm significado, nem se acredita que possam tê-lo, que são vistos como vazios (melhor seria dizer não-vistos). Nesses lugares que resistem ao significado, a questão de negociar diferenças nunca surge: não há com quem negociá-la. O modo como os espaços vazios lidam com a diferença é radical numa medida que outros tipos de lugares projetados para repelir ou atenuar o impacto de estranhos não podem acompanhar (BAUMAN, 2001, p. 99).

Os espaços urbanos ditos vazios devem ser pensados para além de uma visão morfotipológica da arquitetura citadina. Esses espaços devem ganhar um outro 
SILVA FILHO, L.C. da

sentido que reforcem as comunicações voláteis da sobremodernidade. Iremos de encontro com a relação estabelecida entre mundos, onde o mundo que habito tornase modo de banalizar e reduzir a existência de outros mundos. A velocidade a qual transitamos entre espaços torna nossa visão de mundo reduzida a unidades sem multiplicidades. Surge então os lugares assignificantes condicionados.

Todos lugares possuem significados, mas até quando eles possuem significados? Por qual motivo existiria tais movimentos significativos e assignificativos nessa produção? Embora tais perguntas possam ser respondidas de forma prática, pensemos nas possibilidades de construção desses espaços. A negação da existência de transitação nos variados espaços além do estabelecido ou frequentemente constituídos como transitáveis por uma força hegemônica, apagamos do mapa tornando-os vazios. Esses vazios são constituídos e definidos por outros que também habitam a mesma cidade, por muito, próximos a eles, mas o ato de existirem torna conflitante os interesses do habitar e de estar na cidade. "Eles estão em lugares ao qual nenhum significado é atribuído. Eles não precisam ser fisicamente isolados por cercas ou barreiras. Estes não são lugares proibidos, mas espaços vazios, inacessível por causa de sua invisibilidade" (KOCIATKIEWICZ; KOSTERA, 1999, p. 43).

Chegamos ao ponto que os espaços vazios irão além do sentido de não possuírem identidades e nos depararmos com um espaço esvaziado de suas identidades - lugares assignificantes. Esse mecanismo relaciona o que já foi dito até então, mas é caracterizado sobre tudo pelo medo do desconhecido e do não-contato. O estranhamento por novos lugares além do vivencial, reduz espaços a não-espaços. Não por serem muitas vezes espaços excepcionais da cidade ou simplesmente por serem marginalizados, mas por simplesmente não serem espaços que são capturados por outros para si.

Também podemos pensar nas existências de espaços esvaziados como lugares que se constituem na cidade como estéril de reprodução coletiva, social e afetiva 
pelas construções ideais de lugares. Dar-se isso em resposta das produções midiáticas com esses lugares onde as manchetes muitas vezes os descrevem como inseguros e impossíveis de ser o "meu habitar" potencializando as produções.

O medo então é um condicionante de esvaziamento de sentido e identidade dos lugares. Os não-lugares são respostas da sobremodernidade que juntamente se incluem os espaços vazios. Novos artefatos construídos na cidade como shoppings, condomínios, alphaviles, aeroportos, espaços privados entre outros, consequentemente mudam toda a lógica da cidade, colocando em questão os aspectos desiguais e enquanto alguns espaços vão sendo requalificados outros são esquecidos desse processo e criando conjuntos de lugares assignificantes (WENETZ, 2013).

Ao buscarmos uma maneira de compreender esse espaço vazio devemos ir além do sentido propriamente dito, ou seja, como espaços na cidade onde não existem estruturas físicas -materialidade cristalizada na paisagem. Aqui é colocado em questão o além desses espaços construídos ou não, indo de encontro aos espaços que ao longo do tempo se constituí como espaços não transitáveis e assignificativos. Assim são produzidos espaços esvaziados de sentidos e signos.

Com a grande expansão urbana, os polos de mercados espalhados pela cidade e a velocidade que o cotidiano impõe dificultam o relacionamento interpessoal. A relação entre as pessoas e o espaço resulta na utilização das vias somente como passagens, ignorando as construções que as cercam e até mesmo os nomes das ruas que fazem parte do seu itinerário

Pensando buscar a nitidez entre o conceito Deleuzeguattariana ao encontro de múltiplos que não se rompem exclusivamente, mas rompem e se reconectam no transitar, o rizoma se torna fundamental para compreender as expressões materializadas na captura geofotográfica documental, este trabalho traça pontes entre a geografia e a filosofia pós-estruturalista e sobremoderna. 
Utilizamos a etnocartografia e as geofotografias como possibilidade metodológica para compreender e dar visibilidade as multiplicidades existentes na ZEIS - Ilha de Deus. As etnocartografia utilizou da metodologia apresenta por Silva Filho (2021) intitulada de Cartografia Antropofágica das Paisagens e as Geofotografias foram capturadas ao longo de dois anos com o intuito de registrar os movimentos dos sujeitos com mangue na Ilha de Deus.

Assim, temos por objetivo desse trabalho buscar encontrar por meio da razão esquizoanalítica n-1 as multiplicidades de elos que existem na captura da paisagem, nas rupturas e reconecções do real cristalizado e materializado na representação visual-documental dos espaços esvaziados promovidos pela sobremodernidade.

\section{$O$ "n-1" revelador de multiplicidades de elos transitórios nas geofotografias}

A Geofotografia percorre por um caminho que se faz múltiplos no transitar do movimento da vida, que se expande para além das marcas deixadas no solo batido, construído como limites de produção econômica. Ao ancorarmos junto a filosofia esquizoanalítica percebemos que Deleuze e Guattari em Mil platôs, traz uma contribuição importante a luz da questão rizomática. O rizoma é compreendido como possibilidades de conhecer o mundo e aqueles que o habitam, constroem e transformam em um mundo capitalista as cristalizações materiais, como uma estrutura (não-estruturante) horizontal, uma raiz que perfura o solo em variados caminhos, que se faz presente em um variado espaço.

Deleuze e Guattari (1996, p. 14) molda uma estrutura lógica sobre o rizoma, que é um mecanismo fundamental na compreensão do que nos cerca, onde é "preciso fazer o múltiplo, não acrescentando sempre uma dimensão superior, mas, ao contrário, da maneira simples, com força de sobriedade, no nível das dimensões de que se dispõe, sempre n-1". Dessa razão matemática podemos riscar o que é o rizoma em sua forma cristalizada ou não, onde parte do conjunto de variados elementos que significam a paisagem e no profundo do lugar, na terra que estamos, sendo "somente assim que o uno faz parte do múltiplo, estando sempre subtraído dele", onde o " $\mathrm{n}$ " 
seria qualquer unidade existe em um determinado espaço, não devendo ser meramente unidade de um sistema, pois o rizoma foge de uma unidade verticalizada e marcada, mas da sua subtração "-1" que exige e confronta as tentativas de torna-lo único e definindo-o como rizoma. É nas multiplicidades que se faz o rizoma, pois é toda a possibilidade existente menos aquela única a ser estabelecida e então formará essa razão. Pensar o múltiplo é reconhecer sua importância na unidade, no único, no $-1$.

Nesse sentido toda lógica é confrontação de conjuntos abstratos das subjetividades delirantes. Compreender ou tentar compreender é um caminho de tornar o mundo menos abstrato, á logica é modelagem do concreto real, tudo aquilo que podemos materializar a partir da razão. A fotografia é uma confrontação lógica do real cristalizado a partir dos delírios transitados e capturados. É desejo e agenciamento múltiplos. "Uma imagem fotográfica nada quer dizer se não considerada como um agenciamento ligado a outros agenciamentos. Dever-se-ia também afirmar: uma fotografia é um corpo sem órgãos onde não cabem o significante nem o significado, onde não se procurará compreender alguma coisa" (CARVALHO, 2008, p. 2).

A Geofotografia é um rizoma que na sua materialização da captura do movimento do real, resgata a pluralidade, ou melhor, as interrupções das unidades do que pode ser apresentado. Assim, a relação do capturado nas geofotografias se apresenta como elos rizomáticos das manifestações existenciais e relacionais do serno-mundo, são sempre juntos aos outros. Todas as geofotgrafias trazem consigo as expressões Deleuzeguattariana dos variados n-1 Já que um corpo não se faz único em um mundo, sendo ele unidade torna-o múltiplos corpos, não deixando de ser único, porém o faz vários.

Na sobremodernidade cada vez mais a visualização materializada dessa razão se perde com destreza da velocidade a qual o mundo se encontra. Entre o transitar em espaços meramente de passagem, vazios e esvaziados - assignificativos- 
SILVA FILHO, L.C. da

precisamos buscar deslumbrar a multiplicidade nos lugares -e por muito são perdidas ou conduzidas ao esquecimento e apagamento da cidade.

\section{A razão "n-1" nos espaços esvaziados nas geofotografias do ser-mangue na Ilha de}

\section{Deus}

É intrigante adentrar em um lugar que não é nosso - até então - e entre o "transitar" e o "estar" pode estar marcado pela insegurança em resposta as produções do medo agenciadas pelas narrativas de alhures. Observar os detalhes entre as texturas, luz e sombra e as cores em campo torna-se desconfortável enquanto estivermos interligados a esses agenciamentos, mas ao fazermos o exercício de entrega e construção de pontes e elos de confiança entre o nosso "eu" com os espaços e com os outros, conheceremos o mais sutil do ser, seus desejos e devires em seu lugar.

Nesse caminho, enquanto me aventurava nas ruas, na lama, com os moradores e com o menino do mangue, deixava de lado todo o preconceito que sabia que não era meu e então seguia entre as rizomáticas linhas de encontro entre os sujeitosmangue que em resposta era um ser-mangue que não eram "uno", pois a unidade não os representavam, mas eram múltiplos, eram corpora filhos do mangue. Era com a máquina fotográfica que fazia as capturas do transitar transcendental da vida do ser-mangue na ZEIS - Ilha de Deus (Mapa 1).

A ZEIS - Ilha de Deus que está inserida dentro de depósitos de mangues em uma planície antropogênica composta basicamente por pneus, lixo e revestida por uma camada de sedimentos síltico-argilosos e cascalhos biogênicos acumulados ao longo dos anos no intuito de tornar firme a lama sob seus pés. É uma comunidade aos dizeres sociais pobre e carente inserida dentro do limite do bairro do Pina que pertence a cidade do Recife.

Cercada pelos rios Tejipió, Jordão e Pina, influenciam diretamente na dinâmica do abastecimento de água dos viveiros e no transporte de pessoas através de embarcações de pequeno à médio porte. Também é em suas margens e em seu 
canal que os moradores se deslocam para a coleta de caranguejos, mariscos e sururus. A vegetação ao seu arredor é composta basicamente por mangue vermelho (Rhizophora mangle), mangue branco (Laguncularia racemosa) e espécies exóticas inseridas na paisagem ao longo dos anos.

Mapa 1 - Recife: localização da Ilha de Deus.

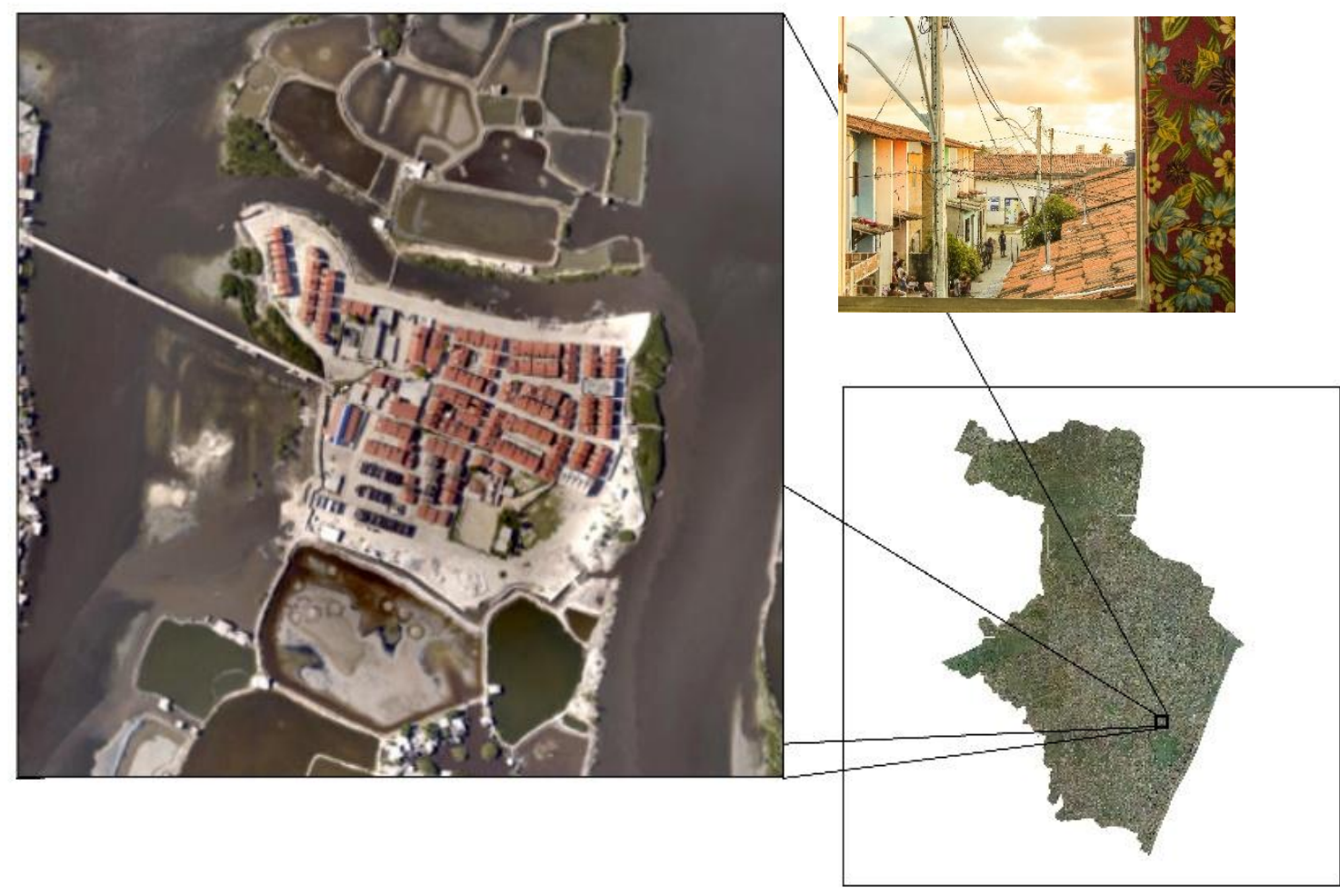

Fonte: elaboração do autor, 2021.

Essa Ilha é composta pelo conjunto de corpora que configura sua realidade. São os ser-sururu, ser-caranguejo, ser-viveiro, ser-camarão, ser-criança que não são unidades, mas são as multiplicidades da Ilha de Deus.

\section{O ser-mangue e o homem-sururu}

A Foto 1 retrata o sujeito em seu ambiente de trabalho e que torna seu corpo como ferramenta além-corpus. Esse sujeito coleta da lama o sururu e internaliza uma rotina árdua. Acorda cedo, espera todo dia o subir e descer natural da maré para 
então ir em busca de coletar esses pequenos animais e trazer as margens do rio para que então possam ser levados para as mulheres e homens da Ilha fazerem a limpeza.

Foto 1 - O homem-sururu e o corpo-ferramenta

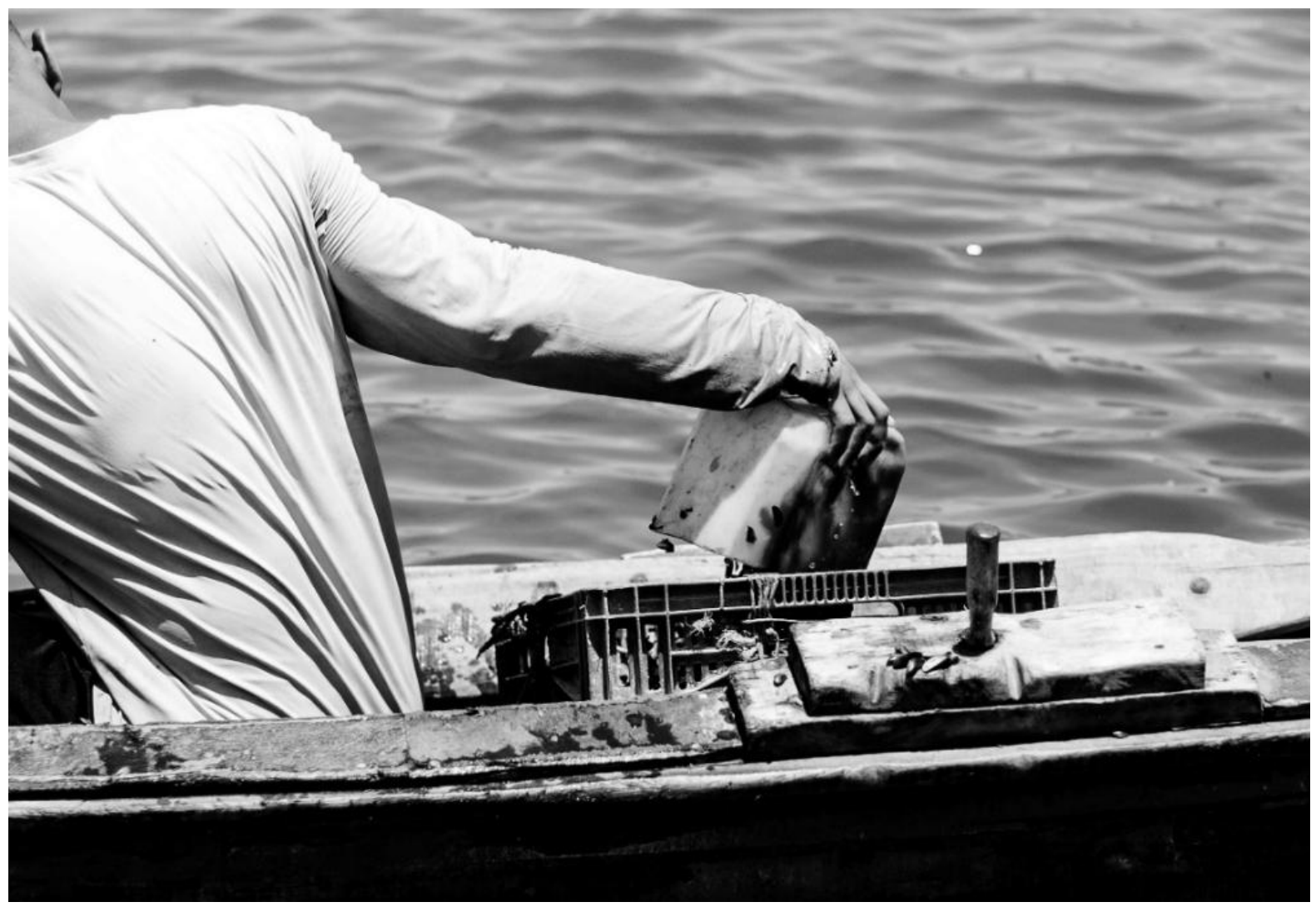

Fonte: Arquivo pessoal do autor, 2021.

A cada dia que se passa, na rotina constituída no íntimo dos sujeitos, deixa marcas naquele espaço à beira do rio. Cada movimento repetido em transferir aqueles pequeninos seres do barco para galeia e da galeia para as ruas e vielas da Ilha de Deus para que outros iniciem seu trabalho. Agora mulheres, homens e crianças começam a fazer a limpeza desses pequenos seres envolto por um sargaço conhecido como bucha pelos moradores.

Cada Sururu limpo, lavado, cozido e embalado para venda, representa um traço marcante da resistência da comunidade Ilha de Deus. Enquanto doutro lado das margens daquele rio alguns renegam a essência e existência desses sujeitos potencializados pelo trabalho, onde enfrentam a bruta realidade do dia-a-dia, onde abandonam por um instante a sua vaidade e a sua segurança ao manusear aqueles 
pequeninos, são os mesmos que se debruçam em busca desse produto comercializados pelos homens e mulheres da Ilha de Deus. Nesse momento eles esquecem quem são e de onde vem ou qualquer preconceito vinculado a sua origem e compram para servir em restaurantes e bares da elite recifense. Cada degustada e cada ápice do sabor proporcionado pelas delicias produzidas, não remetem jamais o seu caminho construído pelos moradores da Ilha de Deus.

\section{Ser-mangue e o mimetismo das capturas capturante}

O sujeito enquanto capturador do animal atribui uma ação mimética em seu capturar (Foto 2). Sua mão se metamorfisa em pinça enquanto o animal que também possui a mesma característica de pinçar, perde sua eficácia em defender-se do sujeito capturante. Era uma máquina de captura constituída pela existência de outros em sua estrutura genealógica do saber compartilhado. Formava-se ali elos de capturas. A captura do caranguejo pelo garoto que tem sua pele contrastada com o cinza do chão, um caranguejo que tem sua ação de pinçar-defesa "roubada" pelo garoto e ressignificada; e pelo geofotógrafo que captura as capturas dos capturados.

Foto $2-\mathrm{O}$ mimetismo da captura.

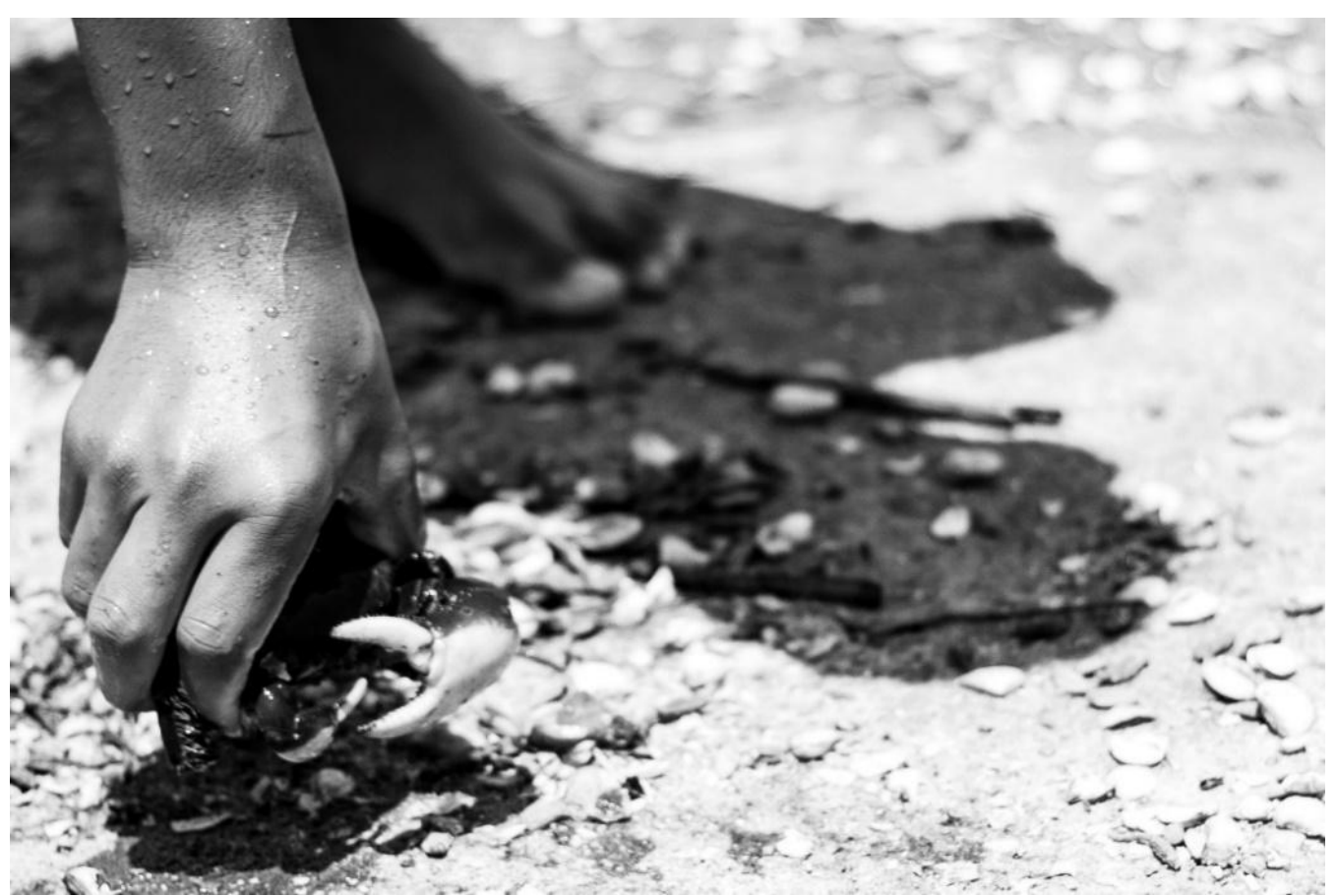

Fonte: Arquivo pessoal do autor, 2021.

Geopauta, Vitória da Conquista ISSN: 2594-5033, V. 5, n.4, 2021, e9756 
Enquanto eu observava e fazia minhas capturas, algumas crianças rapidamente vinham até meu encontro para tentar ensinar-me qual era a forma correta de fazer a captura do caranguejo. Confesso que não foram das mais fáceis lições feitas por mim, mas deveras a mais interessante. A troca a qual me submeti, como o sujeito-observador-fotografo-cartografo e como sujeito que aprendi e reproduz os ensinamentos dado, foram de fato umas das experiências gratificantes a qual me submeti.

\section{Ser-mangue e a rede que nos ligam}

Em um outro lugar tão distinto na Ilha de Deus quando comparamos com as margens do rio Pina, observávamos que agora a individualidade-coletiva vista no capturar dos caranguejos era deixada de lado nos viveiros. Agora a presença do outro era necessária ao longo da despescagem (Foto 3) -atividade de retirar os camarões cultivados para venda.

Foto 3 - Redes rizomáticas

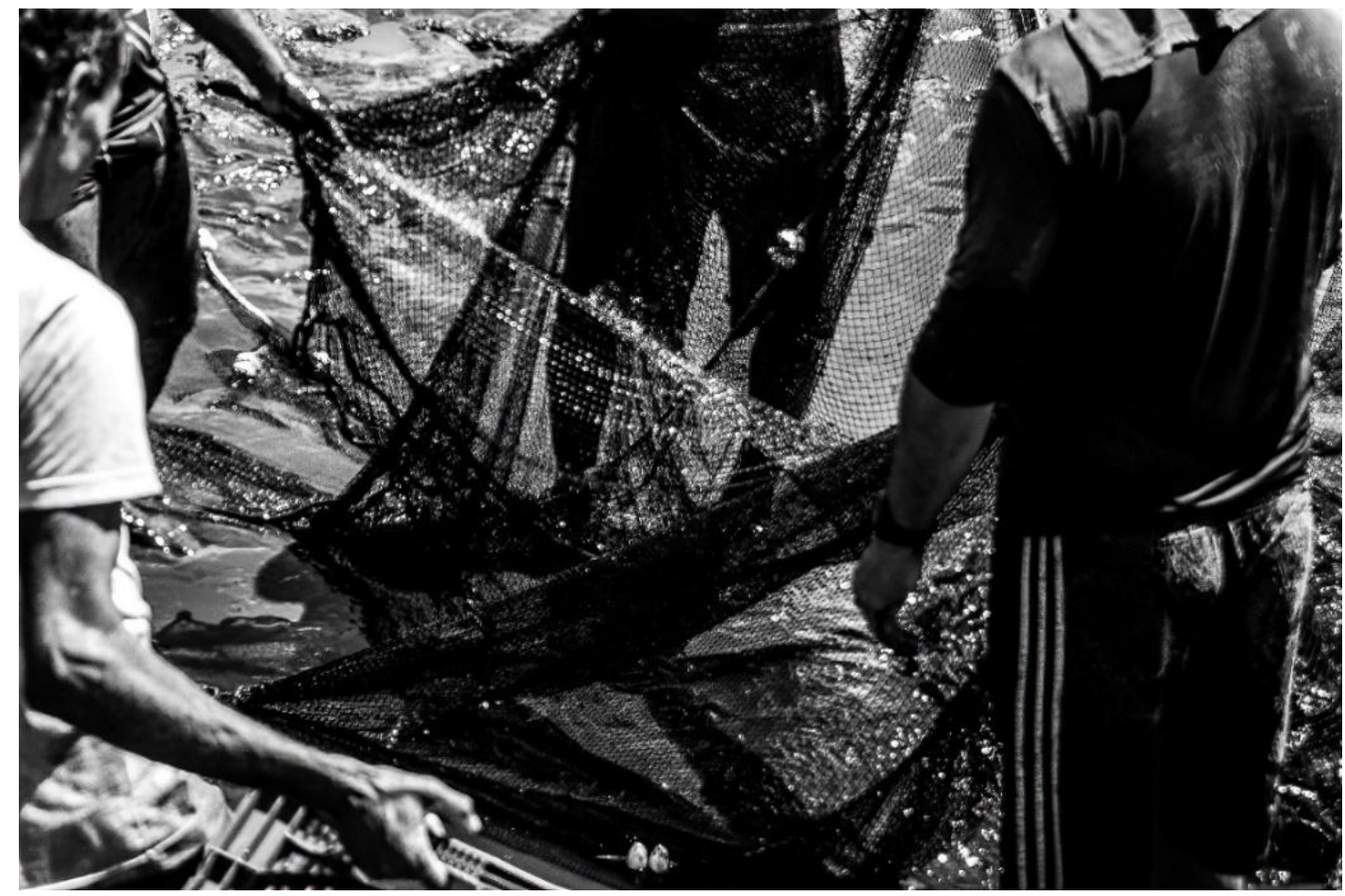

Fonte: Arquivo pessoal do autor, 2021. 
A rede utilizada na despescagem assume a forma rizomática de conexão entre os sujeitos, a razão esquizoanalítica é então deslumbrada em cena. O n-1 é cristalizado no tempo, os corpora presentes na cena são unidades interligadas pela multiplicidade que é a rede. A rede não existe na unidade, mas na conexão dos vários outros que a segura.

Para coletar o camarão sempre se faz presente o outro, em dois, em quatro, em seis e então em vários. O movimento de arraste acontece no estar na lama e na água conhecendo o outro, em passos calmos e seguros percorrem aquele pequeno-enorme espaço. O olhar de quem é de fora nos promove um fervilho de pensamentos, ali com os pés sobre a lama, que por muito são machucados pelos ferrões do animal, formava uma simbiose. Uma mistura entre a lama, o homem e o produto produzindo um sacrifício do homem e do produto, sem dúvida formava-se ali um sujeito-sacrificado.

A invisibilidade do homem-mangue, da lama e da comunidade ganha tons e matéria quando tocamos a mesma lama, o mesmo espaço, fazia vibrar o nosso corpo vibrátil ao entrar em contato com o outro e naquele instante entre o estar e transitar na simbiose do contato que conhecemos e reconhecemos a existência do outro.

Cada produto ali cultivado e coletado é o aurum-mangle da Ilha de Deus. Depois do arraste novamente surge os outros para dar continuidade ao processo. Jovens participam daquele movimento e enchem as galeias com os camarões para serem pesados e comercializados ali mesmo (Foto 4). O viveiro é a unidade que precisa da multiplicidade para ganhar sentido e não se faz pela unidade pois ele por si só não tem a sua função em sua existência solitária. São os corpora que dão sentido aquele lugar, que transitam de um lado ao outro pelos estreitos caminhos que cercam os viveiros, são as mulheres que coletam os camarões que ficam enrolados na rede e os que caem ao chão, são as crianças que aprendem com todos que ali exercitam seu saber tradicional, os homens que arrastam a rede e os jovens com suas pequenas 
redes que entram e pegam o que sobrou para si. É o ser-mangue cristalizado sobre a lama.

\section{Foto $4-$ Aurum-mangle}

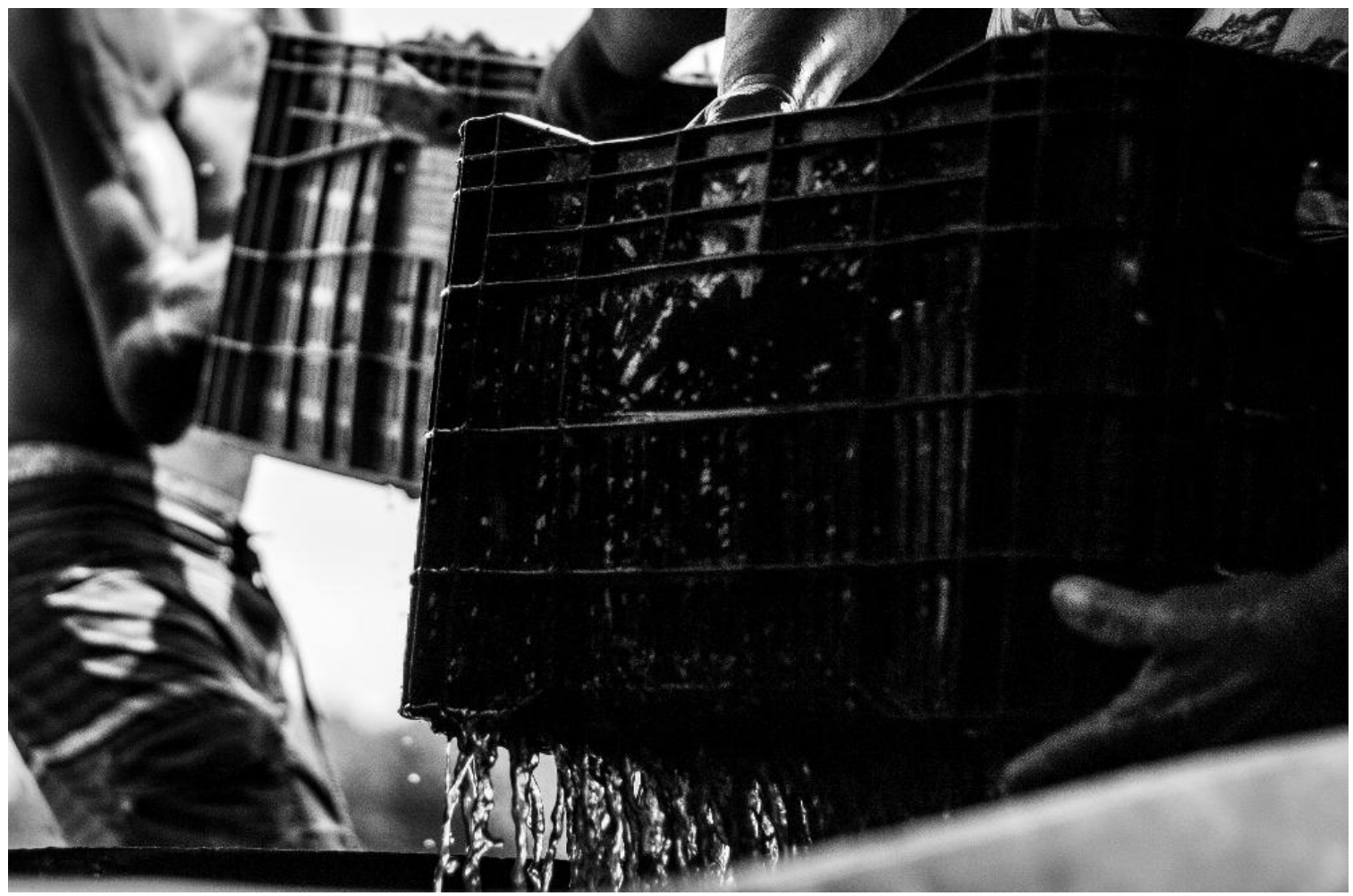

Fonte: Arquivo pessoal do autor, 2021.

\section{O ser-mangue e aqueles que nada-tudo-tem}

Que louco caminho foi sendo feito naquela tão distinta Ilha. Aprender era um movimento de via dupla, sabendo que era como troca, mas não como moeda, mas sim como troca de experiência de vida. Era interessante participar de todo aquele momento que materializava sobre meu olhar. O olhar do cartógrafo externo a aquele lugar, que antes foi coibido pelo medo e agora participa de tudo aquilo realmente era esplêndido. As crianças que ali estavam exerciam um papel quase que despercebido, ali era lugar de aprender a coletar. O coletar ganha um sentido para além do obter apenas os caranguejos, mas como coleta de experiência entre os outros que ali estão.

Os movimentos desajeitados e em construção do capturar-caranguejo estava ligado com a ajuda dos outros. 
Enquanto me movia em busca de fazer as minhas capturas, notava dois meninos a beira da maré praticando a captura. Eu observo-os e atento-me como era estabelecida as formas de capturar aquele animal. Um dos garotos segurava a sua ferramenta - construída provavelmente por um parente- enquanto o outro exercitava o seu mimetismo. Pinçava-os o animal juntos. Ali era dois garotos que nada-tudo-tem. Por morarem na Ilha de Deus são invisibilizados e considerados como seres que pouco tem, na Ilha enquanto habitantes eles tudo tem. É um tudo que perpassa o valor enquanto dinheiro chegando no valor social e cultural que eles adquirem a cada dia. A Ilha de Deus é promoção de valores sociais e culturais, pois serão eles que levaram para o amanhar tudo aquilo que foi adquirido e passado na genealogia do saber compartilhado.

Os caranguejos proveram novos laços, novos momentos. As pessoas passavam em seus barcos, sorriam e acenavam para mim ao ver minha câmera em um gesto de pedir para que eu registrasse o seu momento ali, uma captura que recorta sua essência na paisagem, que nos revela um ser-caranguejo, homem-caranguejo e mulher-caranguejo produzidos ali.

\section{O menino-do-mangue, o eu-cartógrafo e o ser-mangue}

O caminho a qual escolhi tornou-me parte de um novo mundo, encravandome na lama, nas cascas, nos verdes, nas águas e nos rejeitos. Conheci uma sensibilidade a qual não percebia em mim. Fui acolhido e chamado de família, o ethos da confiança (SADE; FERRAZ; ROCHA, 2013) foi firmado ao longo do processo. Se envolver ao longo da caminhada foi fundamental para realizar este trabalho.

Tornava-me parte daquele microuniverso, dos momentos que ocorrem ao longo das marés. Tornava-me Ilha de Deus, o ser-mangue, na tentativa de tornar visível as cores que nem sempre precisam ser compostas para senti-las, mas existem em sua própria existência. 


\section{SILVA FILHO, L.C. da}

E a partir desse caminho que decidi seguir, grandes pessoas estavam ao meu lado, umas que permaneceram no movimento do tempo e outras que se foram para além dos limites humano. Dentre essas pessoas que permaneceram o menino do mangue se fez presente em momentos agenciados por ele no meu transitar pela Ilha de Deus. Desses momentos carrego um elo de compartilhamento e de confiança já que muito dos caminhos ao longo da Ilha foram traçados por ele na tentativa de mostrar-me as mais belas formas e cores que ali existia.

Entre olhares de descobrimento e aprendizado, percorremos por toda imensidão do finito lugar que estávamos. Caminhos que percorremos em aprendizados, em histórias, em atravessamentos da existência. Ao Elias, o menino do mangue, que sempre esteve do meu lado percorrendo, brincando e descobrindo, dedico parte do meu eu-cartografo à sua essência (Foto 6).

Foto 5 - Entre as bordas dos viveiros corria o menino-do-mangue, Elias.

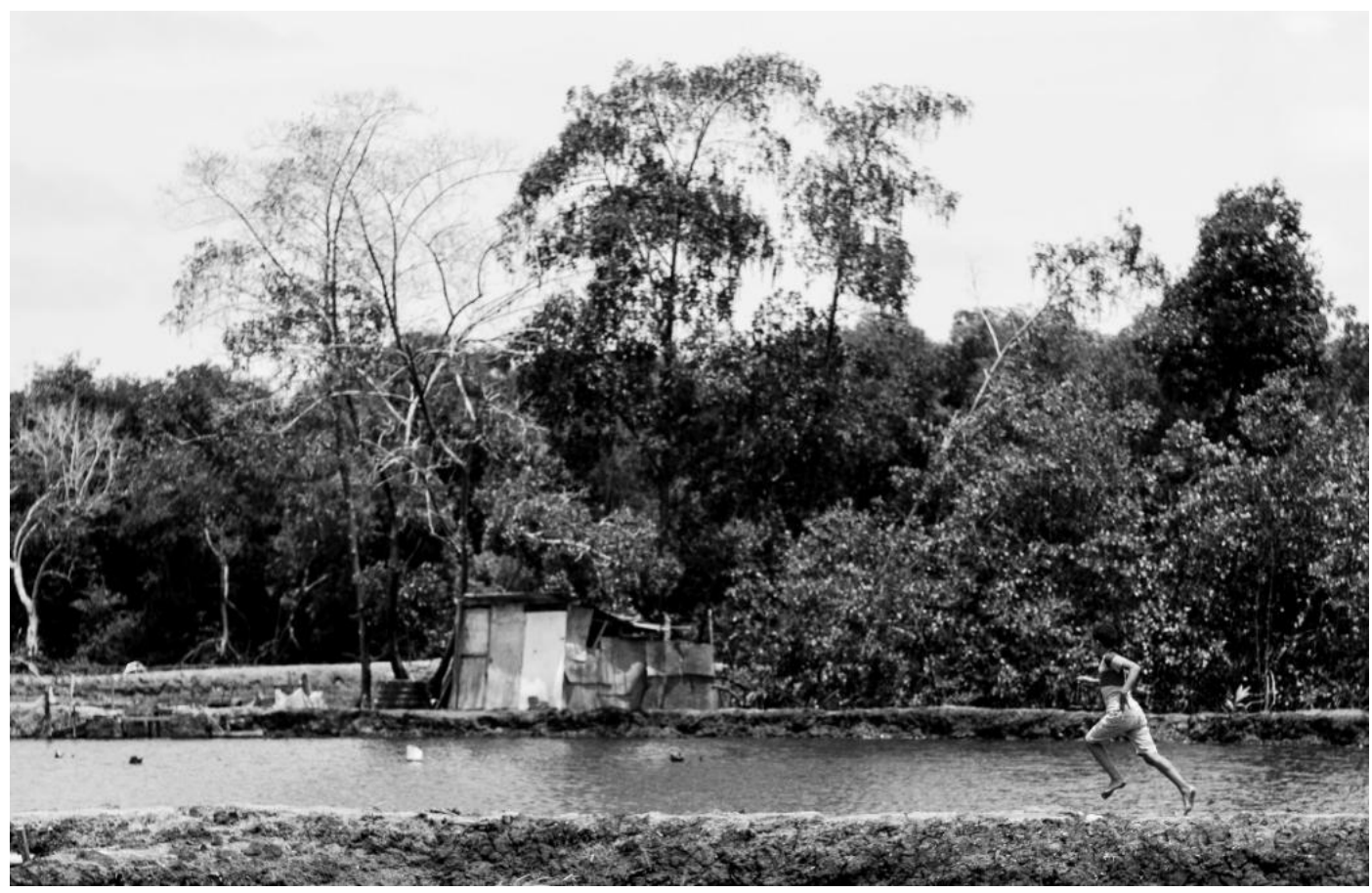

Fonte: Arquivo pessoal do autor, 2021.

Produzimos um conjunto maquínico na relação cartógrafo-menino, meninomangue e cartografo-menino-mangue essências que interagem entre os desejos produzidos em união e camuflação de uma mesma fonte transcendental, a paisagem 
da Ilha de Deus. Ali tornava-me ser-mangue, pois a minha unidade não era importante para o mergulhar na geografia dos afetos. Era preciso ser parte, fazer parte do $n$ da razão esquizoanalítica pois enquanto multiplicidade erámos parte, o meu eu enquanto unidade era tudo aquilo que não se tornaria múltiplo era o -1.

\section{Considerações Finais}

O contato com a Ilha de Deus de início foi constituído pelo medo em resposta dos agenciamentos midiáticos que nos transpassa a todo instante criando essa psicoesfera do medo. $\mathrm{O}$ transitar nos proporcionou $\mathrm{o}$ descobrimento $\mathrm{e} \mathrm{o}$ preenchimento de sentidos e afetividades em um espaço esvaziado por uma expressão -1 que apaga a existência daqueles que preenchem um espaço marginalizado e estigmatizado.

A água, a lama, os camarões, os sururus, os caranguejos são elementos que compões a paisagem da Ilha de Deus e são soma que têm como resultado o coletivo de desejos que fazem com que eles se movimentem no espaço. Cada atividade que se atrela a uma determinada função na ilha é sinônimo de multiplicidade e são interligadas constantemente sem distinção.

A partir dessa relação simbiótica conseguimos planar sobre a Ilha de Deus e vermos em sua essência um rizoma que a interliga há vários pontos existentes na paisagem. A Ilha de Deus se estende entre Ilha de Deus-Território, Ilha de DeusMangue, Ilha de Deus-Viveiro, Ilha de Deus-Despescagem, Ilha de Deus-Sururu, Ilha de Deus-Corpora, Ilha de Deus-Caranguejos. Todos esses elementos produzem momentos, afetos e afetações distintos no tempo, porém semelhantes no espaço.

A construção do Ser-Ilha de Deus é elevada pelo objeto natureza-paisagem, camuflada nos diferentes cenários existentes. Numa visão deleuzeguattariana, observamos que as territorializações constituídas na formação da comunidade, foram sendo desterritorializadas pela subversão de sua existência, marginalizadas pela sociedade, administrando a imagem desfavorecida e incapazes de produzir afeto e 
pertencimento. Mas na medida em que a paisagem promove nos corpos a necessidade de movimento-ressignificação do que é dado como seu, a luta pela reterritorialização se constituiu.

As geofotografias documentais expostas ao longo de toda a obra colaboram no movimento por esse rizoma, no mergulho na lama como movimento de consciência da existência do outro, no ato de comer para reconhecer a existência do outro e na escuta de como reconhecer a necessidade de um todo. Embora ver nem sempre seja um exercício de compreensão, é a possibilidade de se ver nas mais diversas realidades simples, ditas e não ditas à personificação e subjetivação da paisagem. A câmera que utilizamos é uma extensão ótica da captura de enunciados afetivos presentes na paisagem, acompanhando, portanto, suas transformações espaçotemporais. Quando se torna extensão, busca captar o movimento afetivo que pode se materializar tomando formas e quando elas acontecem de fato, registramos o acontecimento manifestado.

Portanto, devemos fazer soma entre as experiências e as relações dos sujeitos com o lugar e com a paisagem que os cercam, pois é dessa forma que faremos com que seja compreendido a relação não-centralizada entre os corpora. As narrativas somada com as fotografias não devem ser entendidas com um olhar de romantização do trabalho ou das condições subnormais a qual vivem, mas que devem ser vistas além, chegando no que há de mais potente nesse lugar. É o múltiplo que importa, são os vários sujeitos que transitam em sincronia com o lugar tornando-se o ser-mangue que ressignificam os espaços esvaziados - lugares assignificantes - para um espaço relacional e afetivo, ou seja, o lugar.

\section{Referências}

AUGÉ, Marc. Não lugares: introdução a uma antropologia da supermodernidade. Campinas: Papirus, 1994. 111 p.

AUGÉ, Marc. Sobremodernidade: do mundo tecnológico de hoje ao desafio essencial do amanha. in: MORAES, D. Sociedade midiatizada. Eio de Janeiro: Mauad, 2006, p. 99-117. 
BAUMAN, Zygmunt. Modernidade Líquida. Rio de janeiro: Jorge Zahar, 2001.

CARVALHO, Paulo de Tarso. Da reversão do platonismo: como funciona uma imagem fotográfica?. In: XXXI Congresso Brasileiro de Ciências da Comunicação, 2008. XXXI Congresso Brasileiro de Ciências da Comunicação, 2008.

DELEUZE, Gilles; GUATTARI, Felix. Mil Platos. 2 ed. São Paulo: Editora34, 1996. v1.

KOCIATKIEWICZ, Jerzy; KOSTERA, Monika. The Anthropology of Empty Spaces. Qualitative Sociology, [S.L.], v. 22, n. 1, p. 37-50, 1999. Disponível em: http://dx.doi.org/10.1023/a:1022131215755. Acesso em: 26 out. 2021.

MARANDOLA JR., Eduardo. Sobre ontologias. In: MARANDOLA JR., Eduardo; HOLZER, Werther; OLIVEIRA, Lívia de (orgs.). Qual o espaço do Lugar?: geografia, epistemologia, fenomenologia. São Paulo: Perspectiva, p. XIII-XVII, 2014.

OLIVEIRA, Lívia. O Sentido de Lugar. In: MARANDOLA JR., Eduardo; HOLZER, Werther; OLIVEIRA, Lívia de (orgs.). Qual o espaço do Lugar?: Geografia, epistemologia, fenomenologia. São Paulo: Perspectiva, p. 3-16, 2014.

WENETZ, I. As crianças ausentes na rua e nas praças: etnografia dos espaços vazios. Civitas - Revista de Ciências Sociais, v. 13, n. 2, p. 346-363, 31 jan. 2014. 